\title{
Interactive effects of endogenous morphine, nitric oxide, and ethanol on mitochondrial processes
}

\author{
Richard M. Kream, George B. Stefano
}

Neuroscience Research Institute, State University of New York - College at Old Westbury, Old Westbury, NY, USA

Submitted: 29 April 2010

Accepted: 19 May 2010

Arch Med Sci 2010; 6, 5: 658-662

DOI: $10.5114 /$ aoms.2010.17077

Copyright @ 2010 Termedia \& Banach

\section{Abstract}

Positive evolutionary pressure has preserved the ability to synthesize chemically authentic morphine, albeit in homeopathic concentrations, throughout animal phyla. The prototype catecholamine dopamine (DA) serves as an essential chemical intermediate in morphine biosynthesis both in plants and animals, thereby providing considerable insight into the roles reciprocal "morphinergic" and catecholamine regulation of diverse physiological processes. Primordial, multi-potential cell types, before the emergence of specialized plant and animal cells/organ systems, required selective mechanisms to limit their responsiveness to environmental noise. Accordingly, cellular systems that emerged with the potential for recruitment of the free radical gas nitric oxide (NO) as a multifaceted autocrine/paracrine signaling molecule were provided with extremely positive evolutionary advantages. Endogenous "morphinergic" in concert with NO-coupled signaling systems have evolved as autocrine/paracrine regulators of metabolic homeostasis, energy metabolism, mitochondrial respiration and energy production. Basic physiological processes involving "morphinergic"/NOcoupled regulation of cardiovascular mitochondrial function, with special emphasis on the interactive effects of ethanol, are discussed within the context of our review.

Key words: endogenous morphine, dopamine, catecholamine, nitric oxide, nitric oxide synthase, ethanol.

\section{Introduction}

Positive evolutionary pressure has apparently preserved the ability to synthesize chemically authentic morphine, albeit in homeopathic concentrations, throughout animal phyla [1-3]. Accordingly, the high level of evolutionary conservation of morphine and related morphinan alkaloids defines these molecules as essential chemical factors required for normal growth and development [4]. Interestingly, dopamine (DA) serves as an obligate chemical intermediate in the morphine biosynthetic pathway in Papaver somniferum without assuming an independent role as the prototype catecholamine signaling molecule with associated phenomena [1, 5-9]. We have formulated a hypothesis stating that catecholamineexpressing signaling systems emerged from the morphine biosynthetic pathway via evolutionary adaptation of key enzymes involved in the modification of L-tyrosine (L-TYR), DA, 3,4-dihydroxy-L-phenylalanine (L-DOPA), and tyramine (TA) [1-4].
Corresponding author: Dr. George B. Stefano Neuroscience Research Institute SUNY College at Old Westbury

P.O. Box 210

Old Westbury, NY 11568

Phone: 001-516-876-2732

Fax: 001-516-876-2727

E-mail:

gstefano@sunynri.org 
Operationally, catecholamine and endogenous "morphinergic" signaling systems share a common set of biosynthetic and metabolic enzymes, indicating significant evolutionary retrofitting of primordial enzyme species [2, 3, 10-12]. Mitochondria arose via permanent enslavement of purple nonsulphur bacteria as endosymbionts [13, 14]. Accordingly, primordial "morphinergic"/nitric oxide (NO)-coupled signaling may have been instrumental in the establishment of the mitochondrion as a viable eukaryotic organelle. Aberrant "morphinergic"/NO-coupled regulatory events at the mitochondrial level are proposed as causative factors in a variety of pathophysiological states that associated with very basic metabolic dysfunction. Interestingly, we have observed that sub-threshold concentrations of ethanol alter cellular distributions of endogenously expressed morphine. Reciprocal autocrine/paracrine modulatory effects of very low concentrations of morphine in concert with ethanol also suggest the potential for endogenous expression and action of homeopathic concentrations of ethanol within discrete cellular microdomains, in particular mitochondria.

\section{Functionally coupled catecholamine and morphinergic expression in animal cells: modulation by low levels of ethanol}

Catecholamine signaling systems have evolved as mainstay regulators of integrated physiological and organ systems in animals, whereas "morphinergic" signaling systems have evolved as autocrine/paracrine regulators of metabolic homeostasis, energy metabolism, and mitochondrial respiration [3, 4]. Homeopathic expression of endogenous morphine appears to exert a statedependent down-regulation of cellular excitability via highly specific receptor mediated processes within a highly confined local circuitry [15-18]. In a previous review, we have suggested that evolutionary pressure drove an adaptive expansion of catecholamine signaling systems in animal phyla commensurate with the acquisition of complex motor activities associated with complex feeding, sexual and protective processes [4].

Previous work from our laboratory has demonstrated that $1 \%$ ethanol engenders a significant enhancement of cellular levels of endogenous morphine when administered to in vitro tissue preparations $[6,19,20]$. Whereas the cellular effects of $1 \%$ ethanol may be functionally linked to its anesthetic properties [21-25], a 100 fold lower concentration of $2 \mathrm{mM}$ ethanol, equivalent to a non-activating, sensitizing, dose of $0.01 \%$ was observed to produce an effective doubling of ${ }^{125} \mathrm{I}$-trace labeled morphine released into the extracellular medium. Because DA and its immediate precursors L-TYR, L-DOPA, and TA also serve as biosynthetic intermediates in cellular morphine expression [26, 27], ethanol-mediated anesthetic inhibition of dopamine signaling may effectively divert excess precursor molecules to cellular morphine pools.

\section{Endogenous morphine and nitric oxide-coupled regulation of cardiovascular mitochondria}

We have proposed that the expression of endogenous morphine by animal and human cells is designed to mediate homeopathic regulation of metabolic activity via activation of cognate $\mu_{3}$ and $\mu_{4}$ receptors that serve as transductive conduits for short-circuit $\mathrm{Ca}^{++}$fluxes $[28,29]$. Interactive regulatory pathways employing endogenously expressed morphine as an activating principle for $\mathrm{Ca}^{2+}$-dependent, graded release of NO were fashioned as a key cellular signaling molecule, responsible for regulating intermediary metabolic functions, including mitochondrial respiratory rate [30].

Cardiovascular physiology apparently involves concerted regulatory activities of endogenous morphine and $\mathrm{NO}$ at the cellular level. In an ischemia-reperfusion rat model administration of pharmacological dosages of morphine has been shown to reduce infarct size in the myocardium and promote improvement in cardiac function [31, 32]. Additionally, the protective effects of morphine have been attributed to the opening of mitochondrial K(ATP) channels in the myocardium [30, 33-38]. Subsequent studies have demonstrated that morphine protects the myocardium against ischemia-reperfusion injury via inhibition of

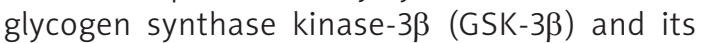
facilitation of mitochondrial permeability transition pore opening (mPTP) [39, 40]. Operationally, morphine protects the ischemic myocardium against $\mathrm{Ca}^{2+}$-induced MPTP opening with subsequent increases in mitochondrial resistance and inactivation of GSK-3 $\beta$ via PI3-kinase mediated events [40]. A recent review has indicated that a major cardio-protective effect of morphine is mediated through enhanced mitochondrial hexokinase binding [41]. The authors speculate that many cardio-protective interventions, including ischemic preconditioning and morphine administration during postconditioning, direct cellular redistribution and target mitochondrial of hexokinase.

Constitutive NO production and release protects the ischemic heart from apoptosis and mitochondrial dysfunction via protein kinase G-mediated blockade of MPTP opening and cytochrome c release [42] Furthermore, in a rat postconditioning ischemia-reperfusion interactive positive effects of morphine and constitutive NO were observed [43]. Extensive pharmacological controls using opiate 


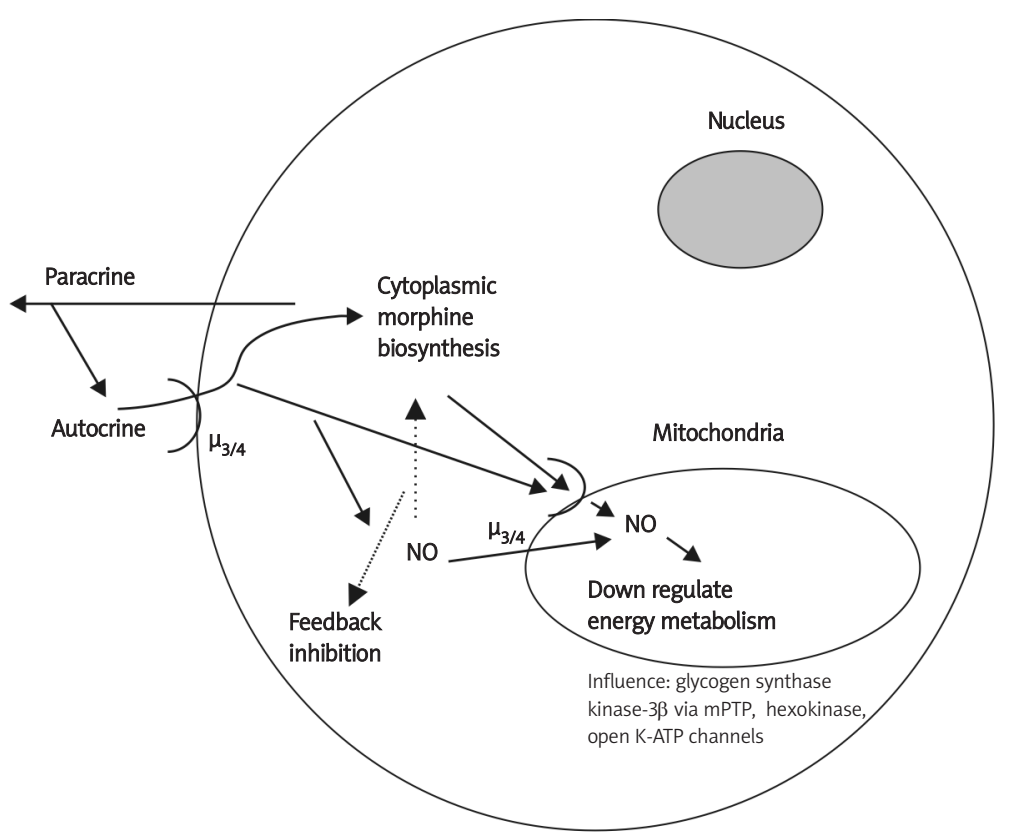

Figure 1. Human white blood cells have the ability to make and release morphine, which can have autocrine and paracrine signaling functions. In the case of autocrine via cell surface $\mu_{3 / 4}$ receptors nitric oxide would be released given its coupling to these mu opiate receptor subtypes. Additionally, $\mu$ opiate receptors, as noted in the text, are on mitochondrial membranes. We speculate that the stimulated cellular NO can exert negative feedback actions on the enzymes that make morphine and simultaneously negatively influence key mitochondrial energy associated enzymes and processes, as noted in the figure, which when taken in total diminishes energy metabolism. In so doing we surmise ROS and tissue damaging processes will be diminished, thus, morphine exerts an overall protective effect. We also surmise, it is this morphinergic influence that may allow the mitochondria to be enslaved as a cellular organelle via diminishing its ability to generate uncontrolled ROS and energy (from [7])

receptor antagonists, constitutive nitric oxide synthase (cNOS) and protein kinase inhibitors, provided validating evidence for selectivity of effect via concerted inhibition of MPTP opening by morphine and activation of the cNOS-protein kinase $G$ pathway. A concerted pharmacological approach has recently been developed to selectively target NO donor compounds to mitochondria as an efficacious strategy to modulate respiration and protect mitochondria against ischemia-associated reperfusion injury [44].

\section{Endogenous morphine and nitric oxide-coupled regulation of cardiovascular mitochondria: involvement of ethanol}

Our demonstration of dose dependent effects of ethanol on endogenous morphine expression may have profound implications for development of novel therapeutic approaches for cardiovascular protection. Epidemiological studies suggest that light to moderate ethanol consumption not only prevents ischemic cardiovascular damage but also improves survival after myocardial infarction [45]. Clinical indications are complemented by a relatively recent preclinical study investigating the interactive protective effects of $2.5 \%$ ethanol on anesthetic preconditioning in isolated guinea pig hearts [46].
The investigators demonstrated that infarct size was significantly reduced in anesthetic and ethanol treated hearts, as compared to controls. Importantly, the interactive effects of ethanol resulted in enhanced opening of mitochondrial K(ATP) channels and a coordinate increase in cNOS expression with a reduction of inducible nitric oxide synthase (iNOS) expression. In conclusion, reciprocal autocrine/paracrine modulatory effects of very low concentrations of morphine in concert with NO and ethanol suggest the potential for endogenous expression and action of homeopathic concentrations of ethanol within cardiovascular mitochondria.

\section{References}

1. Kream RM, Stefano GB. De novo biosynthesis of morphine in animal cells: an evidence-based model. Med Sci Monit 2006; 12: RA207-19.

2. Kream RM, Mantione KJ, Sheehan M, Stefano GB. Morphine's chemical messenger status in animals. Activitas Nervosa Superior Rediviva 2009; in press.

3. Stefano GB, Kream RM. Dopamine, morphine, and nitric oxide: An evolutionary signaling triad. CNS Neurosci Therap 2009; in press.

4. Stefano GB, Kream RM. Endogenous morphine synthetic pathway preceded and gave rise to catecholamine synthesis in evolution. Int J Mol Med 2007; 20: 837-41. 
5. Kream RM, Stefano GB. Homeopathic ethanol. Med Sci Monit 2008; 14: SC11-3.

6. Zhu W, Esch T, Kream RM, Stefano GB. Converging cellular processes for substances of abuse: endogenous morphine. Neuro Endocrinol Lett 2008; 29: 63-6.

7. Kream RM, Stefano GB. Endogenous morphine and nitric oxide coupled regulation of mitochondrial processes. Med Sci Monit 2009; 15: RA263-8.

8. Stefano GB, Esch T, Kream RM. Xenobiotic perturbation of endogenous morphine signaling: paradoxical opiate hyperalgesia. Med Sci Monit 2009; 15: RA107-10.

9. Stefano GB, Kream RM, Esch T. Revisiting tolerance from the endogenous morphine perspective. Med Sci Monit 2009; 15: RA189-98.

10. Mantione K, Kream RM, Stefano GB. Variations in critical morphine biosynthesis genes and their potential to influence human health. REVIEW. Neuro Endocrinol Lett 2010; 31: 9.

11. Mantione KJ, Zhu W, Kream RM, Esch T, Stefano GB. Regulation of the transcription of the catechol-O methyltransferase gene by morphine and rpinephrine. Activitas Nervosa Superior Rediviva 2010; in press.

12. Sheehan M, Kream RM, Mantione KJ, Stefano GB. Prediction of a novel "short" $u$ opiate receptor in domestic chicken. Activitas Nervosa Superior Rediviva 2010; in press.

13. Cavalier-Smith T. Origin of mitochondria by intracellular enslavement of a photosynthetic purple bacterium. Proc Biol Sci 2006; 273: 1943-52.

14. Mastronicola D, Arcuri E, Arese M, et al. Morphine but not fentanyl and methadone affects mitochondrial membrane potential by inducing nitric oxide release in glioma cells. Cell Mol Life Sci 2004; 61: 2991-7.

15. Stefano GB, Scharrer B. Endogenous morphine and related opiates, a new class of chemical messengers. Adv Neuroimmunol 1994; 4: 57-68.

16. Stefano GB. Autoimmunovascular regulation: morphine and anandamide stimulated nitric oxide release. J Neuroimmunol 1998; 83: 70-6.

17. Stefano GB, Goumon Y, Bilfinger TV, Welters I, Cadet P. Basal nitric oxide limits immune, nervous and cardiovascular excitation: human endothelia express a mu opiate receptor. Prog Neurobiol 2000; 60: 513-30.

18. Stefano GB, Goumon Y, Casares F, et al. Endogenous morphine. Trends Neurosci 2000; 9: 436-42.

19. Bae MK, Jeong DK, Park NS, et al. The effect of ethanol on the physical properties of neuronal membranes. Mol Cells 2005; 19: 356-64.

20. Zhu W, Mantione KJ, Casares FM, et al. Alcohol-, nicotine, and cocaine-evoked release of morphine from invertebrate ganglia: model system for screening drugs of abuse. Med Sci Monit 2006; 12: BR155-61.

21. Santamaria F, De SS, Montella S, et al. Nasal nitric oxide assessment in primary ciliary dyskinesia using aspiration, exhalation, and humming. Med Sci Monit 2008; 14 CR80-5.

22. Tanii H, Higashi T, Nishimura F, Higuchi Y, Saijoh K. Effects of cruciferous allyl nitrile on phase 2 antioxidant and detoxification enzymes. Med Sci Monit 2008; 14: BR189-92.

23. Yokusoglu M, Sag C, Cincik M, et al. Perindopril, atenolol, and amlodipine prevent aortic ultrastructural changes in rats exposed to ethanol. Med Sci Monit 2008; 14: BR96-102.

24. Pflueger A, Abramowitz D, Calvin AD. Role of oxidative stress in contrast-induced acute kidney injury in diabetes mellitus. Med Sci Monit 2009; 15: RA125-36.

25. Yokoyama H, Hirose H, Saito I. Two types of unsafe drinker judged to have metabolic syndrome: typical metabolic syndrome or alcohol-related syndrome? Med Sci Monit 2009; 15: H57-64.
26. Zhu W, Mantione KJ, Shen L, et al. Tyrosine and tyramine increase endogenous ganglionic morphine and dopamine levels in vitro and in vivo: CYP2D6 and tyrosine hydroxylase modulation demonstrates a dopamine coupling. Med Sci Monit 2005; 11: BR397-404.

27. Zhu W, Cadet P, Baggerman G, Mantione KJ, Stefano GB. Human white blood cells synthesize morphine: CYP2D6 modulation. J Immunol 2005; 175: 7357-62.

28. Fimiani C, Mattocks DW, Cavani F, et al. Morphine and anandamide stimulate intracellular calcium transients in human arterial endothelial endothelial cells: coupling to nitric oxide release. Cell Signal 1999; 11: 189-93.

29. Nieto-Fernandez FE, Mattocks DW, Cavani F, Salzet M, Stefano GB. Morphine coupling to invertebrate immunocyte nitric oxide release is dependent on intracellular calcium transients. Comp Biochem Physiol 1999; 123: 295-9.

30. Stefano GB, Neenan K, Cadet P, Magazine HI, Bilfinger TV. Ischemic preconditioning - An opiate constitutive nitric oxide molecular hypothesis. Med Sci Monit 2001; 7: 1357-75.

31. Chang WL, Lee SS, Su MJ. Attenuation of post-ischemia reperfusion injury by thaliporphine and morphine in rat hearts. J Biomed Sci 2005; 12: 611-9.

32. Peart JN, Gross GJ. Adenosine and opioid receptormediated cardioprotection in the rat: evidence for crosstalk between receptors. Am J Physiol Heart Circ Physiol 2003; 285: H81-9.

33. Ludwig LM, Patel HH, Gross GJ, Kersten JR, Pagel PS, Warltier DC. Morphine enhances pharmacological preconditioning by isoflurane: role of mitochondrial K(ATP) channels and opioid receptors. Anesthesiology 2003; 98: 705-11.

34. Cohen MV, Yang XM, Liu GS, Heusch G, Downey JM. Acetylcholine, bradykinin, opioids, and phenylephrine, but not adenosine, trigger preconditioning by generating free radicals and opening mitochondrial K(ATP) channels. Circ Res 2001; 89: 273-8.

35. McPherson BC, Yao Z. Morphine mimics preconditioning via free radical signals and mitochondrial K(ATP) channels in myocytes. Circulation 2001; 103: 290-5.

36. Chistiakov VV, Gegenava GP. Mechanism of opiateinduced permeability of mitochondrial membranes for potassium ions. Biokhimiia 1980; 45: 492-7.

37. Chistiakov VV, Gegenava GP. Mechanism of opiate of oxidative phosphorylation in mitochondria. Biokhimiia 1976; 41: 1272-8.

38. Gegenava GP, Chistiakov VV. Effect of morphine in vitro on the oxidative phosphorylation in rat liver mitochondria. Biull Eksp Biol Med 1975; 80: 77-9.

39. Gateau-Roesch O, Argaud L, Ovize M. Mitochondrial permeability transition pore and postconditioning. Cardiovasc Res 2006; 70: 264-73.

40. Obame FN, Plin-Mercier C, Assaly R, et al. Cardioprotective effect of morphine and a blocker of glycogen synthase kinase 3 beta, SB216763 [3-(2,4-dichlorophenyl)-4(1methyl-1H-indol-3-yl)-1H-pyrrole-2,5-dione], via inhibition of the mitochondrial permeability transition pore. J Pharmacol Exp Ther 2008; 326: 252-8.

41. Zuurbier CJ, Smeele KM, Eerbeek O. Mitochondrial hexokinase and cardioprotection of the intact heart. J Bioenerg Biomembr 2009; 41: 181-5.

42. Borutaite V, Morkuniene R, Arandarcikaite O, Jekabsone A, Barauskaite J, Brown GC. Nitric oxide protects the heart from ischemia-induced apoptosis and mitochondrial damage via protein kinase $\mathrm{G}$ mediated blockage of permeability transition and cytochrome c release. J Biomed Sci 2009; 16: 70. 
43. Jang $Y, X i$ J, Wang $H$, Mueller RA, Norfleet EA, Xu Z. Postconditioning prevents reperfusion injury by activating delta-opioid receptors. Anesthesiology 2008; 108: 243-50.

44. Prime TA, Blaikie FH, Evans C, et al. A mitochondriatargeted S-nitrosothiol modulates respiration, nitrosates thiols, and protects against ischemia-reperfusion injury. Proc Natl Acad Sci U S A 2009; 106: 10764-9.

45. Miyamae M, Kaneda K, Domae N, Figueredo VM. Cardioprotection by regular ethanol consumption: potential mechanisms and clinical application. Curr Drug Abuse Rev 2010; 3: 39-48.

46. Kaneda K, Miyamae M, Sugioka S, et al. Sevoflurane enhances ethanol-induced cardiac preconditioning through modulation of protein kinase $\mathrm{C}$, mitochondrial KATP channals, and nitric oxide synthase, in guinea pig hearts. Anesth Analg 2008; 106: 9-16. 